\title{
Muscle metabolism and atrophy: let's talk about sex
}

\author{
Megan E. Rosa-Caldwell and Nicholas P. Greene
}

\begin{abstract}
Skeletal muscle health is a strong predictor of overall health and longevity. Pathologies affecting skeletal muscle such as cancer cachexia, intensive care unit treatment, muscular dystrophies, and others are associated with decreased quality of life and increased mortality. Recent research has begun to determine that these muscular pathologies appear to present and develop differently between males and females. However, to our knowledge, there has yet to be a comprehensive review on musculoskeletal differences between males and females and how these differences may contribute to sex differences in muscle pathologies. Herein, we present a review of the current literature on muscle phenotype and physiology between males and females and how these differences may contribute to differential responses to atrophic stimuli. In general, females appear to be more susceptible to disuse induced muscle wasting, yet protected from inflammation induced (such as cancer cachexia) muscle wasting compared to males. These differences may be due in part to differences in muscle protein turnover, satellite cell content and proliferation, hormonal interactions, and mitochondrial differences between males and females. However, more works specifically examining muscle pathologies in females are necessary to more fully understand the inherent sex-based differences in muscle pathologies between the sexes and how they may correspond to different clinical treatments.
\end{abstract}

Keywords: Muscle atrophy, Disuse, Cancer cachexia, Mitochondria, Hormones, Sex differences

\section{Background}

Muscle makes up 47-60\% of lean body mass in men and women and is one of the greatest contributors to whole body energy expenditure [1]. Therefore, maintaining skeletal muscle health is critical to maintaining health and longevity throughout the lifetime. Various pathological conditions, such as prolonged periods of disuse, cancer cachexia, burn injuries, and others cause dramatic muscle atrophy, which in turn relates to a decrease in overall quality of life and increased mortality [2]. Specifically, disuse atrophy, a common occurrence with prolonged bed rest, casting, and space-flight, develops rapidly and significantly increases mortality and morbidity in these populations [2, 3]. For example, muscle loss occurs rapidly in intensive care unit (ICU) patients, and the degree of muscle loss is associated with increased treatment time and mortality [4-7].

\footnotetext{
* Correspondence: npgreene@uark.edu

Integrative Muscle Metabolism Laboratory, Exercise Science Research Center, Department of Human Health Performance and Recreation, University of Arkansas, Fayetteville, AR 72701, USA
}

Interestingly, these disuse-induced pathologies appear to discriminate between biological sexes, with females tending to have faster onset of muscle loss compared to males [8] which has been postulated to correspond to increased mortality in females [9]. However, until recently, investigations into disuse pathologies have primarily been conducted in only one sex [10-20] despite the influence of biological sex in many diseases [21-26]. However, the differences and similarities between males and females during atrophic pathologies is not currently codified. Therefore, the purpose of this review is to examine the current literature on various physiological processes between males and females potentially contributing to muscle health, including general muscle phenotype, response to catabolic and anabolic stimuli, hormonal contributions to muscle health, as well as mitochondrial profiles.

\section{Muscle phenotypes between males and females}

The maintenance of muscle size relies on a delicate balance between protein synthesis and degradation, 
whereby an increased protein synthesis:degradation ratio results in muscle hypertrophy and decreased synthesis:degradation ratio results in muscle atrophy. Many diseases are associated with reduced health outcomes with muscle loss [27, 28]. Recent works have established that mechanisms contributing to these muscle pathologies are different depending on the disease, making effective treatment options difficult. For example, cancer is also known to cause marked muscle and body fat loss, with body weight losses being strongly associated with mortality. However, this particular form of atrophy appears to be related to the inflammatory action of the tumor-host interactions [29-32], whereas disuse atrophy does not typically display this classical inflamed phenotype [33]. Until recently, it was thought that processes contributing to muscle loss were not sex specific. However, recent works have begun to establish differences between males and females on responsiveness to atrophic and hypertrophic stimuli. In this section, we will specifically focus on sex differences in overall muscle phenotype and how these differences may contribute to differential sensitivity to catabolic and anabolic factors as well as highlight areas for further research (Fig. 1).

\section{Fiber type differences between males and females and susceptibility for disuse atrophy}

Data have begun to demonstrate muscle composition differences between males and females. Females tend to rely more on oxidative metabolism compared to males [34]; correspondingly, females also have greater relative content of type I muscle fibers compared to males within the same muscle $[35,36]$. Works have previously established that different muscle pathologies differently affect different muscle fibers [37], with cancer cachexia more strongly influencing glycolytic fibers compared to oxidative [38-40] and disuse atrophy preferentially selecting for oxidative fibers [14, 33, 41]. Although it is not completely understood why disuse atrophy more radically impacts oxidative fibers, the differential content of fibers between males and females may be an important consideration for future research investigating sex as a biological variable with muscle atrophies.

\section{Disuse muscle loss between males and females}

While muscle loss occurs in both males and females across a variety of pathologies, different pathologies appear to differentially affect males and females [8, 9, 42-46]. For example, during aging-induced atrophy, females experience a greater shift toward smaller fibers compared to males [47]. However, during inflammation-based muscle pathologies, such as cancer cachexia, males tend to have greater muscle losses and subsequent side effects compared to females [43-45, 48]. Overall, these works suggest that males and females exhibit differing muscle atrophy responses depending on the precise stimuli. Specific to disuse atrophy, female mice have been shown to exhibit a greater percent loss of soleus mass compared to males during hindlimb unloading

\section{Muscle Phenotype

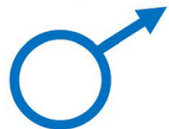 \\ - More glycolytic fibers ${ }^{34-36}$ \\ - More sensitive to inflammation-mediated atrophy 8 $^{38,40,43-45,48}$ \\ - More at satellite cells and greater satellite cell proliferation compared to females ${ }^{59-62}$ \\ - Greater ubiquitin-proteasome activity, less autophagy activity compared to females ${ }^{78-82}$ \\ - Testosterone-mediated myostatin activation $^{99,100}$}

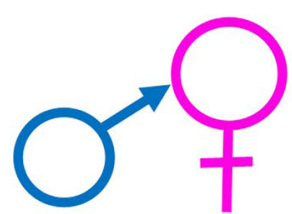

- More oxidative fibers ${ }^{34-36}$

- More sensitive to disuse atrophy ${ }^{8,14,33,41,49}$

- Less satellite cells and reduced satellite cell proliferation compared to males ${ }^{59-62}$

- Greater autophagy activity, less ubiquitinproteasome activity compared to males ${ }^{78-82}$

- Myostatin sensitivity increased compared to males, unclear mechanism for myostatin regulation ${ }^{49,98}$

\footnotetext{
- Similar mTOR activation in response to anabolic stimuli such as: Resistance Exercise and food consumption ${ }^{51-55}$
}

Fig. 1 Summary of current literature of sex differences and similarities of muscle phenotype in males and females 
[49], suggesting females may be particularly susceptible to disuse atrophy compared to males. However, it is not currently clear if this is due to a higher percentage of disusesusceptible type I fibers in females or innate differences in muscle physiology. Clinically, recent works suggest that females are more likely to succumb to intensive care unit (ICU)-associated muscle weakness [8], potentially leading to more ICU-associated deaths [9]. Taken together, these data clearly suggest different responses to atrophic stimuli between males and females and highlight the need for further research investigating mechanisms for muscle wasting across a variety of pathologies.

\section{Sex difference in anabolic and catabolic factors}

As the maintenance of muscle mass depends on the balance of anabolic and catabolic factors, here we will briefly describe known differences between males and females on mediators of protein synthesis and degradation. Briefly, one of the major mediators of protein synthesis is the mammalian target of rapamycin (mTOR). Activation of mTOR by anabolic stimuli (resistance exercise, insulin, amino acids, etc.) results in phosphorylation of 4EBP-1 and S6K1 proteins, allowing for mRNA translation and subsequent protein synthesis [50]. In general, most studies have found that males and females have similar mTOR activation and subsequent protein synthesis with anabolic stimuli such as food consumption or resistance exercise [51-55]. However, there still remains some controversy on sex differences with regards to anabolic processes. For example, some literature has suggested increased protein synthesis measured by fractional myofibrillar synthesis rates in females compared to males with whey ingestion [56], whereas others have found males to have greater increases in muscle protein synthesis compared to females after weeks of sprint interval training [57]. Regardless, the current literature tends to favor no sex-mediated differences on mTOR activation and subsequent protein synthesis [51-55].

Conversely, recent evidence suggests potential sex differences in satellite cell activation and proliferation. Briefly, satellite cells are myogenic stem cells, activated during regenerative stimuli, such as resistance exercise or muscle damage [58]. Once activated, satellite cells proliferate to form new myonuclei and facilitate muscle hypertrophy or regeneration, depending on the specific stimuli [58]. A more through overview of satellite cell activation and proliferation has been reviewed elsewhere [58]. Male satellite cells appear to have more mRNA related to differentiation and hypertrophy such as myogenin and MyoD compared to females [59] and appear to also have greater proliferative capacity compared to females [60,61]. For example, it was recently found that young male mice tend to have greater numbers of satellite cells compared to female mice [61], satellite cells derived from male poultry also have greater proliferation in vitro [60]. These differences may in part be due to differences in testosterone-mediated satellite cell proliferation [62]. For example, in vitro culture of satellite cells treated with serum from castrated males demonstrate reduced proliferation compared to serum from uncastrated males [63]. In vivo loss of testosterone in various mammalian species results in reduced satellite cell content and reduced muscle size [64, 65]. Furthermore, adding supplemental testosterone in males mitigates these aberrations and can result in greater overall satellite cell content compared to control animals [64-66]. This hypothesis of testosteronemediated satellite cell proliferation is further corroborated by research finding testosterone treatment in female mice produced an increase in the number of myonuclei [67]. Taken together, the aggregate of these studies strongly suggest that testosterone mediates greater satellite cell content in males, possibly allowing for greater muscle size. However, we should note that there has been recent controversy on the necessity of satellite cells for maintenance of muscle mass and hypertrophy [68-70]. Such controversies are beyond the scope of this review article; for further information, the reader is directed to excellent reviews on this topic [58, 71]. Overall based on the current literature, females and males do not appear to have clinically meaningful differences in mTOR activation and subsequent protein synthesis in response to anabolic stimuli; however, males do appear to have greater satellite cell content and proliferative capacity compared to females.

Catabolic factors and signaling mechanisms also play a large role in the overall muscle size. Broadly speaking, the two primary protein degradative pathways include ubiquitin-proteasome and autophagy pathways [72]. Briefly, the ubiquitin-proteasome system involves tagging old or misfolded proteins with small ubiquitin proteins; these ubiquitin-tagged proteins are then transferred to the proteome for degradation [73]. This system is regulated by various ligases (referred to as E1, E2, and E3 ligases) that facilitate activation of the ubiquitin, transfer of the ubiquitin to the target protein, and finally the attachment of ubiquitin to the target protein respectively [73].The ubiquitin-tagged protein is then shuttled to the proteasome for degradation and recycling of amino acids [73]. MuRF1 and Atrogin1 are important E3 ligases within the ubiquitin-proteasome pathway and are activated across a variety of catabolic muscle pathologies [73-75]. Similarly, the autophagic degradative pathway serves to remove damaged or old proteins [76]. Autophagy-related genes (Atgs) are the primary regulators of this pathway. Broadly speaking, catabolic stimuli signal to ULK1 protein to initiate 
autophagosomal formation, which is initiated by the Beclin (Atg6) protein [77]. Autophagosomal formation is facilitated by the activation of the LC3I to LC3II conversation induced by Atg4 [77]. Concurrently, the p62 (SQSTM1) cargo protein brings the proteins tagged for autophagosomal degradation to the autophagosome. Finally, the autophagosome binds with a lysosome for lysosomal degradation of the protein [77]. A more through overview of these process has been reviewed elsewhere [73, 77].

Recent works have begun to tease out the nuances in possible differences of these pathways between males and females. In general, it appears that both of these processes are at least partially mediated by biological sex, as prior works have found mRNAs related to these processes are differentially expressed between males and females [78]. Specifically females overall tend to have lower basal ubiquitin-proteasome activity compared to males, which is thought to be partially mediated by estrogen signaling $[79,80]$. This lowered ubiquitin-proteasome activity appears to result in differential FOXO3a-Ubiquitin signaling during disuse atrophy, with females showing less FOXO3a content compared to males, yet greater ubiquitinated protein content [49]. Potential reasons or mechanism for this differential signaling during disuse have yet to be elucidated. While females tend to have less ubiquitinproteasome activity compared to males, females tend to have greater autophagy-related protein degradation compared to males [81, 82]. Current literature suggests greater protein content of autophagy regulators of autophagy initiation and resolution compared to males [81, 82], overall suggesting that males and females may preferentially favor different protein catabolic pathways.

Specific to disuse atrophy, both males and females have potent inductions of degradative pathways with disuse $[83,84][10,12,85-93]$. However, these responses may be partially mediated by biological sex. For example, male rats and mice undergoing hindlimb unloading have increased Atrogin 1 and MuRF1 induction in the early stages of disuse $(\sim 2-10$-fold depending on length of unloading and tissue) [10, 12, 85-90]. Comparatively, females potentially have an augmented response compared to males, with some studies reporting as much as 20-40-fold increases in MuRF1 and Atrogin1 respectively [83, 84], though others have noted only 2-4-fold greater Atrogin1 and MuRF1 mRNA in hindlimb casted females [91]. Taken together, these studies may suggest similar degradative pathways in males and females during disuse atrophy; however, in females, degradative pathways such as ubiquitinproteasome may be relatively greater compared to males. However, to our knowledge, this hypothesis has not been directly tested and may warrant further study. Similarly, autophagy is also known to be activated during disuse atrophies in both human and animal models [91, 92, 94]. However, potential sex differences in autophagy induction during disuse atrophy have not been directly evaluated between sexes.

Finally, males and females may differ in regulators of protein catabolism, specifically myostatin sensitivity. Myostatin, a protein within the TGF- $\beta$ family, can greatly impact muscle size, with increased myostatin activity contributing to reduced muscle size in multiple models of muscle catabolism [95-97]. While myostatin will affect both sexes, females appear to be more responsive to myostatin withdrawal, with inhibition of myostatin causing greater muscle hypertrophy in females compare to males [98]. However, myostatin action in both sexes still remains perplexing as recent works have found disuse atrophy to increase myostatin content in females but not males [49]. This may be partially due to myostatinandrogen receptor reciprocity. Prior works have found myostatin translation and secretion moderated by androgen receptor translocation to the nucleus with androgen binding $[99,100]$. Speculatively, this interaction between androgen receptor activity and myostatin synthesis may serve to counter balance androgen hypertrophic action. This hypothesis would align with noted differences in myostatin content between males and females during disuse atrophy; however, more works are needed to fully elucidate these complicated interactions.

Overall, the current literature appears to suggest multiple differences in muscle physiology between males and females, as well as a few similarities between the biological sexes. Males and females appear to have similar inductions of protein synthetic pathways with anabolic stimuli and both have large inductions of catabolic pathways with disuses; however, the relative strength of these inductions may warrant further research. Females tend to have more oxidative type I fibers compared to males [34-36], which may predispose females to greater muscle losses with disuse atrophy. Females tend to have less satellite cells $[60,61]$, which may be partially mediated by testosterone-activation of ARs on the satellite cells [64-66]. Females also tend to have less basal ubiquitin-proteasome activity and greater autophagy activity compared to males [79-82]. Finally, females appear to have differential regulation of myostatin activity and subsequent alterations to muscle physiology [49, 98]. Taken together, the aggregate of these data suggest differential interactions between muscle pathologies and biological sex, strongly suggesting the need for research investigating treatment interventions that optimize specific cellular mechanisms that differ between males and females in order to optimize therapies for musculoskeletal pathologies based on biological sex. 


\section{Hormonal interactions}

One significant difference between males and females that likely contributes to dimorphic responses between sexes during muscle pathologies is differing circulating hormones. The process of synthesizing these hormones begins at the gonadotropic cells in the anterior pituitary gland of the brain. Gonadotropes facilitate signaling to sex organs for the synthesis of sex hormones. Different genetic expression within the gonadotropes at the anterior pituitary gland vary in mammals depending on age and menstrual/estrous cycling status. Among females, greater activation of gonadotrope signaling to sex organs is present during proestrus (corresponding to increased estrogen and progesterone synthesis) compared to diestrus [101]. In general, sex hormones exert beneficial effects on muscle mass maintenance and function [102-104]; however, their specific impacts on skeletal muscle may have specificity to the sex of the organism. While it is unlikely that hormones solely mediate differences in muscle health, it is likely that hormonal interactions have at least some influence on muscle quality and health. For the purpose of this review, we will focus primarily on the three primary sex-related hormones: testosterone, estrogen, and progesterone (Fig. 2).

\section{Testosterone as a mediator of muscle growth}

Testosterone is currently one of the most popular supplements in the USA, with sales of testosterone supplements increasing 500\% between 1993 and 2000 [105], and continuing to grow. Men tend to have greater testosterone than women, with a normative range of 82-257 ng/dL for young men and $0.8-10 \mathrm{ng} / \mathrm{dL}$ for young women [106]. Testosterone is an androgenic hormone that works through the action of androgen receptors (AR) on various tissues to facilitate protein anabolism. Specifically, part of this anabolic response involves AR translocation to the nucleus to act as a transcription factor to increase myotube and muscle protein synthesis [107, 108]. Previous work has demonstrated that testosterone can work specifically through ARs to contribute to increased protein synthesis $[107,108]$. In human primary myotubes from men, recent work has clarified the pathways for testosterone action [107]. Specifically, it has been demonstrated that testosterone action can activate mTOR through androgen-mediated action of androgen receptor to activate PI3k/Akt signaling [107]. AR receptor content varies based on the type of tissue, and in muscle by the fiber type [109]. Interestingly, AR activation seems to favor a shift toward slow twitch fibers, with AR-knockout mice demonstrating a shift toward type II fibers [99]. In animal models, removing testosterone in male mice by castration induces a noted decrease in muscle size $[99,110,111]$. Whereas, when testosterone is given to those with low levels of testosterone, such as men with hypogonadism or older male mice, there appears to be increased muscle mass $[110,112]$. In females, testosterone also appears to have anabolic effects, for example postmenopausal women given an acute treatment with testosterone exhibit increased fractional protein synthesis rates [113]. However, that same study found greater FSR in older

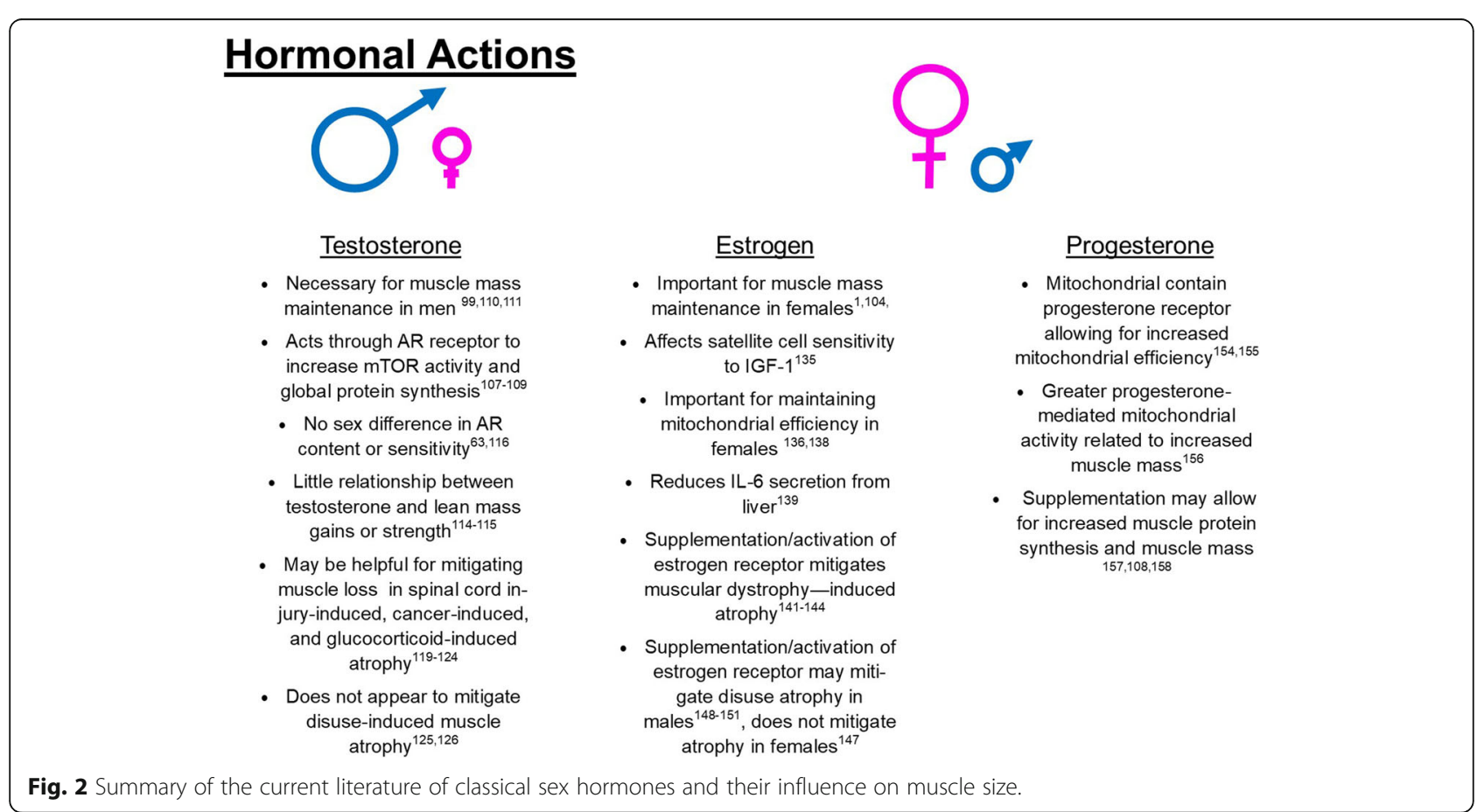


females compared to young [113] as such, it is unclear if increasing protein synthesis rates alone necessitates a phenotypic change in the muscle in this population.

Whereas AR content appears necessary for appropriate muscle fiber size, it does not appear sufficient to induce muscle hypertrophy; for example, resistance exercise training does not appear to impact the number of AR [114]. Additionally, free testosterone in the blood has litthe relationship to changes in lean body mass or strength $[114,115]$. Finally, there does not appear to be sex differences in the number of ARs or sensitivity to anabolic stimuli $[63,116]$, suggesting that sex differences in androgenic activity are likely due to higher concentrations of androgens in the blood.

During multiple muscle pathologies, hypogonadism and associated testosterone concentrations are known to be lowered and hypothesized to partially contribute to muscle loss [117-121]. For example, men with spinal cord injury demonstrate generally lower testosterone levels compared to non-injured controls [122]. However, testosterone supplementation in these populations has shown promise for mitigating this muscle loss in men [119, 120]. Hypogonadism also commonly accompanies cancer cachexia $[117,118]$, and recent works have begun to evaluate the sufficiency of drugs with androgen-like binding and testosterone itself as pharmacological agents for the treatment of cancer cachexia in men [123, 124]. Finally, testosterone supplementation appears to limit glucocorticoid-induced muscle atrophies in male mice [121]. However, despite these promising findings in other muscle pathologies, testosterone status does not appear to influence muscle mass recovery from hindlimb unloading, in that androgen supplementation in these populations does not mitigate muscle losses $[125,126]$. Therefore, while the presence of testosterone appears to be a necessary component for muscle mass and quality in males, the precise relationships between testosterone status and muscle quality appear dependent on the specific muscle pathology. Overall, it does not appear that testosterone treatment is necessarily effective for mitigating disuse-induced muscle loss in males. However, mechanisms for these discrepancies between different muscle pathologies remain under investigated and warrant further research.

\section{Estrogen as a mediator of muscle growth}

Estrogen (also sometimes referred to as estradiol) is primarily associated as a female sex hormone whose concentration varies throughout the course of the menstrual (human) or estrous (murine) cycle. Specifically, women tend to have increased estradiol and progesterone during the luteal phase of menstrual cycle $(300 \mathrm{pg} / \mathrm{ml}$ estradiol/day and $10 \mathrm{ng} / \mathrm{ml}$ progesterone/day during the luteal phase vs. $50 \mathrm{pg} / \mathrm{ml}$ estradiol/day and $1 \mathrm{ng} / \mathrm{ml}$ progesterone/day during the follicular phase, respectively) [127]. In female mice, estradiol and progesterone appear to peak at $40-60 \mathrm{pg} / \mathrm{ml}$ and $25-30 \mathrm{ng} / \mathrm{ml}$ respectively during proestrus and 7-10 pg/ml and $5 \mathrm{ng} / \mathrm{ml}$ during diestrus [128-132]. Each of these phases affects energy utilization and bioenergetics [133]. Estrogen overall appears to exert a hypertrophic effect [134], which is at least partially mediated by increased sensitivity of IGF-1 in satellite cells [135]. Estrogen also affects mitochondrial health $[136,137]$, whereby estrogen removal in ovariectomized rats decreases mitochondrial $\mathrm{O}_{2}$ consumption and efficiency [136, 138], overall suggesting that estrogen plays an important role for cellular and likely muscular health in females.

While the specific role of estrogen on muscle size and quality is still controversial, in general, deficiency of estrogen is likely detrimental to muscle function in both males and females [1]. Generally, ovariectomized young mice and postmenopausal women have smaller muscles compared to functional uterus controls [1], suggesting that estrogen plays a role in muscle size, at least in females. Estrogen also may be important for protection from atrophic stimuli. For example, during inflammation-induced atrophy, estrogen diminishes IL-6 secretion from the liver and appears to blunt atrophy [139]. This finding strongly suggests protective effects of estrogen and may partially account for differences seen between males and females during pathologies such as cancer cachexia, whereby cycling females do not experience cachexia compared to acyclic females who do undergo cachexia [140]. Estrogenbased treatments have begun to be investigated for various muscular dystrophies [141-144], specifically the use of tamoxifen, a drug developed for estrogendependent breast cancer. Finally, loss of estrogen receptors delays muscle regeneration and differentiation after injury [145]. Overall, the aggregate of the literature appears to suggest that estrogen is a necessary component of muscle size, with reduction or elimination of estrogen causing reduced muscle size and regenerative capacity. However, it should be noted that one study suggested activation of estrogen receptors in males to cause muscle atrophy through increased ubiquitin-specific peptidase 19 content and potential augmented activation of the ubiquitinprotease system [80], and recent work suggests that estrogen treatment in males can alter MHC gene expression as measured through microarray analysis in cardiac tissue [146]. Therefore, more research may be necessary to understand the intricacies of estrogen's precise effects on muscle in both males and females.

Specific to disuse muscle atrophy, estrogen treatment and/or supplementation has shown mixed efficacy on protections against disuse-induced muscle pathologies. For example, ovariectomized mice showed delayed recovery 
from disuse-induced atrophy, and greater muscle loss (measured by cross sectional area) compared to ovariectomized mice with estrogen replacement [104], suggesting that estrogen may be a necessary component to mitigate the intensity of muscle atrophy. However, other work shows estrogen treatment in female mice to have little effect on muscular deteriorations with disuse [147], suggesting that estrogen treatment in females is not sufficient to counteract disuse atrophy. Contrastingly, estrogenbased treatments (including both estrogen and estrogenreceptor agonists) have shown some protections against disuse atrophy in male mice and rats [148-151]. Further demonstrating the necessity to investigate potential treatments against muscle pathologies in both male and female models.

Overall, the current literature appears to suggest that estrogen is a major mediator of muscle quality, with loss of estrogen associated with decreases in muscle quality. Supplementation of estrogen may increase muscle size in animals; however, more research using both male and female models are necessary to understand the full influence of estrogen on muscle quality and size.

\section{Progesterone and muscle health}

Similar to estrogen, progesterone also is associated as a female sex hormone, with massive increases in progesterone concentrations during the luteal phase of the menstrual cycle. However, compared to estrogen, progesterone has not been studied as extensively in relation to muscle quality.

One of the early investigations of progesterone found progesterone treatment on myotubes increased hydrogen peroxide (ROS) emission from the mitochondria [152], which the authors interpreted as pathological. However, based on this study, it is not clear whether this emission is necessarily pathological, as small amounts of ROS production may benefit mitochondrial and muscle health as seen in exercise studies where blunting ROS response blunts exercise adaptations [153]. Recently, is has been suggested that mitochondria contain a progesterone receptor that can directly mediate and increase mitochondrial respiration and efficiency $[154,155]$. This increased respiration in the muscle may allow for the increased ATP production necessary to develop and maintain muscle mass. However, to our knowledge, this relationship has not been directly tested in mammalian species.

With specific regard to muscle hypertrophy, high feed efficiency broiler chickens have been found to have higher mitochondrial efficiency which appears to be mediated by progesterone action [156]. This work adds to the growing body of literature that mitochondrial health is a major mediator of muscle quality and this quality is at least partially mediated by progesterone action. Additionally, in cattle, feed efficiency can be increased $~ 20 \%$ by supplementation with progesterone [157], and progesterone treatment in mice and humans can stimulate cardiac and skeletal muscle protein synthesis [108, 158]. However, to our knowledge, no work has directly investigated the role of progesterone on disuse or other muscle atrophies. Based on works demonstrating progesterone's hypertrophic capacity, progesterone treatment may be an additional treatment target for pharmacological interventions for the prevention of muscle atrophies. However, more works are needed to thoroughly understand progesterone's mechanism of action for regulation of muscle quality.

\section{Estrous cycle in relation to muscle pathologies}

Recent literature is beginning to examine the influence of estrous/menstrual cycle on various pathologies and treatments in females. Currently, the aggregation of literature suggests that estrous cycle can influence some pathologies. For example, female mice are more sensitive to the effects of antidepressants during proestrus $[159,160]$ and other pathologies such as autoimmune diseases are thought to be mediated by estrogen and the estrous/menstrual cycle [161, 162], suggesting that hormonal status may influence some disease pathologies. Specific to muscle pathologies, recent work has strongly suggested that estrous cycle may influence development of cancer cachexia in female mice, whereby it is hypothesized that cancer cachexia may influence estrous cycling and result in muscle wasting [140, 163]. For example, in female $\mathrm{Apc}^{\mathrm{min} /+}$ mice, $100 \%$ of acyclic females become cachectic as opposed to essentially no cycling females becoming cachetic [140]. This acyclicity appears to occur in $\sim 38 \%$ of female $\mathrm{Apc}^{\mathrm{min} /+}$ mice [140]; however, mechanisms for this cessation are not yet fully understood. These works suggest that the presence or absence of the estrous cycle influences muscle maintenance in cancer cachexia; however, these differences develop over the course of weeks. With the relatively short time frame of many disuse studies $(\sim 3-14$ days) $[10,11,92,164]$, and the accelerated development of atrophy therein, it is unlikely that the presence or absence of cycling dramatically influences the progression of disuse atrophy. However, this hypothesis has not been directly investigated, therefore more research directly investigating the influence of estrous cycle during disuse atrophy is likely warranted.

Taken together, the aggregate of the current literature suggests that hormones can significantly influence overall muscle health and size. With loss of testosterone or estrogen dramatically influencing muscle size in males and females respectively $[1,104,117-122,134,145]$. However, the potential for supplementation or pharmacological activation of these specific receptors has mixed results depending on the sex of the model organism and muscle 
pathology $[125,126]$ [119-121, 123, 124, 141-144]. These data imply the necessity of research using both male and female organisms to more fully elucidate the influences of these hormones on muscle pathologies and potential treatment efficacy. Finally, progesterone, the traditionally classified female hormone has recently emerged as a potential regulator of mitochondrial and muscular health [154-156]. These recent findings warrant further research on the potential mechanisms of progesterone during muscle pathologies and possible therapeutic applications of progesterone during various muscle pathologies.

\section{Mitochondrial differences between males and females}

Mitochondrial quality has been a recently proposed mediator of muscle size and function [108]. Females in general tend to preferentially oxidize fat as the primary energy substrate $[34,165,166]$, aligning with a greater relative content of type I fibers $[35,36]$. Therefore, suggesting females' higher reliance on mitochondrial oxidative phosphorylation for ATP synthesis. To date, multiple studies have found mitochondrial function, morphology, and content to differ between males and females. Indeed, animal and human studies across multiple tissues have found higher mitochondrial content per gram of tissue and greater transcription factors associated with mitochondrial biogenesis in females compared to males [165, 167-170]. Female gastrocnemius muscles have greater mitochondrial content and mtDNA per gram of tissue compared to males as well as more ATP synthase, TFAM protein, and mitochondrial complexes [168]. These differences appear to correspond to greater mitochondrial activities [167]. Additionally, in other tissues, such as the liver, females have greater mitochondrial content, and respiratory capacity $[169,170]$. Taken together, these data demonstrate that some aspects of mitochondrial quality appear inherently different between males and females, which may contribute to differential progressions of mitochondrially related pathologies including muscle atrophies (Fig. 3).

\section{Sex differences in mitochondrial aberrations during catabolic stimuli}

Recent data suggests that mitochondrial alterations during catabolic stimuli appear to discriminate between males and females. During arthritis-induced disuse, females experience a large decline in subsarcolemmal mitochondrial density compared to males [35, 46]. Additionally, females have greater reductions in the mitochondrial translation protein TFAM compared to males with aging-associated muscle wasting [171] and female mitochondria tend to make less ATP compared

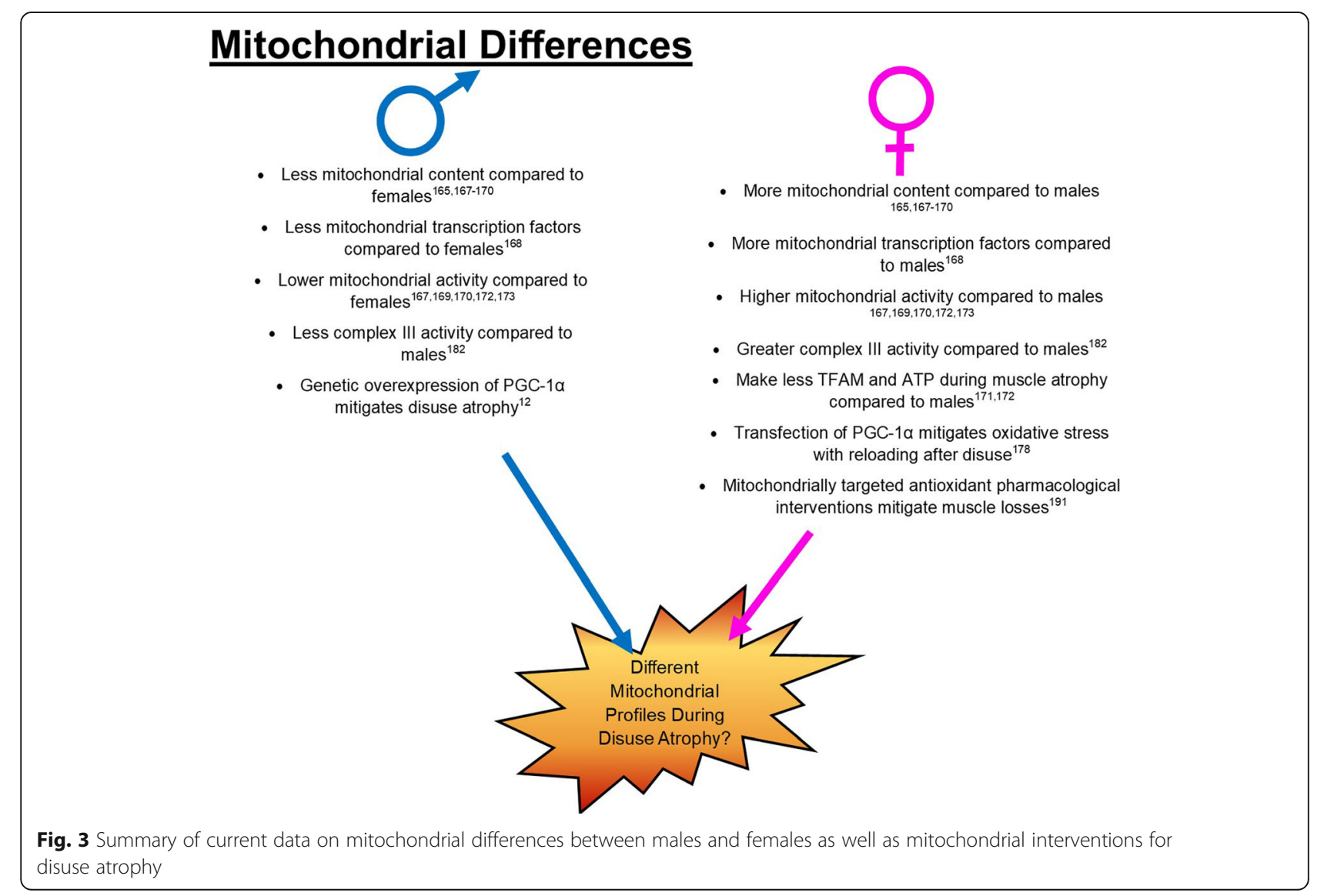


to males during energetic stress such as glucose deprivation in vitro [172]. Overall demonstrating that females and males have different mitochondrial responses to cellular stress, emphasizing the need to further understand how female muscle differs from male, both during basal and stressed conditions. Recent research examining primary cells from males and females have demonstrated sexual dimorphisms on measures of mitochondrial function [172, 173], clearly demonstrating that sex differences are not solely hormone mediated and need to be further investigated using in vivo and in vitro methods. Overall, while it is generally well known that females have differing mitochondrial profiles compared to males, both at baseline and during differing pathologies, it is not directly clear how these differences may influence overall phenotypic and clinical outcomes.

\section{Mitochondrial aberrations during disuse atrophy}

Research throughout the past 25 years has demonstrated that disuse atrophy increases reactive oxygen species (ROS) and peroxide species production [13, 15-19, 174]. Because mitochondria are the primary generators of ROS, efforts to increase mitochondrial quality and function are being investigated as a therapeutic modality for disuse atrophy. For example, multiple studies have investigated the therapeutic potential of antioxidant treatments such as vitamin E supplementation. However, the results of these studies have been mixed with some data showing vitamin E supplementation to be protective [20, 175], whereas others have not seen any protective effects of supplementation [12, 13]. Additionally, because alterations in PGC$1 \alpha$, mitochondrial quality, and oxidative phosphorylation have been noted as substantial contributors to disuse muscle wasting [14, 91, 176], efforts to improve these markers have been investigated as possible therapeutic agents. Overexpression of PGC- $1 \alpha$ in $\mathrm{C} 2 \mathrm{C} 12$ myotubes inhibits protein degradative pathways [177]. In vivo, genetic overexpression of PGC- $1 \alpha$ in male mice mitigates some phenotypic characteristics of disuse atrophy [12], whereas local transfection of PGC- $1 \alpha$ in the tibialis anterior of female mice mitigates some measures of oxidative stress associated with reloading after disuse [178]. Additionally, mitochondrially targeted antioxidant treatment has shown some promise in female rats for the prevention of disuse atrophies [91].

However, despite these promising findings, no current clinical treatments have yet been developed based on these findings. This may be partially due to the disparity in pre-clinical research in female models. Females generally have more mitochondria [168]; while it may be appealing to conclude that females are inherently protected against mitochondrial-related pathologies such as muscle wasting, to date this hypothesis has not been directly tested in disuse pathologies. More so, greater mitochondrial content does not necessarily translate to greater mitochondrial and cellular health, as we and others have demonstrated that genetic induction of mitochondrial biogenesis via PGC- $1 \alpha$ overexpression does not protect against, and may exacerbate, other muscle pathologies such as insulin resistance [179-181]. Additionally, greater mitochondrial content per gram of tissue weight also presents the opportunity for greater ROS production during pathological stimuli. ROS production is thought to occur primarily through complex III within the mitochondria [182], and some evidence suggests that females may have greater complex III activity compared to males [183]. Overall suggesting that mitochondrial differences between males and females may potentially explain differences noted between males and females during disuse pathologies.

\section{Mitochondria and sex hormones}

It is becoming more and more accepted that the mitochondria also contain receptors specific to classical sex hormones that may influence sexual dimorphisms in mitochondrial-related pathologies. For example, estrogen receptors (specifically ER $\beta$ ) have been found in the mitochondrial membrane across multiple tissues [184-190]. The ER $\beta$ is currently thought to increase transcription of nuclear- and mitochondrial-encoded proteins involved in oxidative function and of NRF-1 and COX complexes [191], leading to overall increased mitochondrial oxidation and potentially improved function [192, 193]. ER $\beta$ and ER $\alpha$ total content do not currently appear to differ between males and females [194, 195], thereby suggesting that ER-mediated differences between males and females are likely the result of differences in plasma hormone circulation. Androgen rectors have in some studies been noted on the mitochondria; however, this has been limited to mitochondria present in mobile sperm [196], as such, the influence ARs may have on mitochondrial and cellular function is likely limited [191]. Recently, progesterone action has been hypothesized to alter mitochondrial oxidative function. It has been established since the 1990s that during the luteal phase of the female menstrual cycle (when progesterone peaks), energy expenditure and mitochondrial respiration increase [197-199]. However, recent works have established the presence of a progesterone receptor specific to the mitochondrial membrane (PR-M) $[154,155]$. This PR-M appears to facilitate increased cellular respiration within the mitochondria [154, 155], overall suggesting that progesterone may greatly influence overall mitochondrial and muscular health. However, the potential direct and indirect effects of hormonal actions and mitochondrial quality during muscle atrophies requires further investigation. 
In aggregate, the current literature suggests inherent differences between males and females on both mitochondrial content and function [165, 167-170]. These differences may at least partially contribute to differential mitochondrial alterations during muscle pathologies and subsequent muscle loss [35, 46, 171]. However, many of these differences in disuse specific muscle loss have yet to be investigated as well as global differences in mitochondrial function during pathologies. As such, more research on mitochondrial-specific alterations during muscle pathologies between males and females is necessary to develop more effective therapeutics for mitochondria-related pathologies.

\section{Perspectives and significance}

Skeletal muscle size and quality remain one of the largest mediators of overall quality of life and mortality across a variety of pathologies. Clearly, males have been preferentially researched in pre-clinical models, resulting in a relative dearth of research on muscle pathologies in females. However, the current research demonstrates that males and females are clearly different on many aspects of muscular health and physiology including muscle fiber composition, anabolic and catabolic pathways, hormonal interactions, and mitochondrial content and function. These differences can greatly influence the development and progression of various muscle atrophies, including disuse atrophy. However, specific studies investigating how any of these processes are differentially regulated between males and females in relation to muscle loss are lacking, specifically disuse studies. This lack of data has clear therapeutic implications; less than half of pharmacological agents move to phase 3 clinical trials [200], often due to lack of efficacy in human models. Part of this lack of efficacy in human models is likely partially attributable to lack of female model organisms in pre-clinical and phase I trials. If we are to fulfill the promise of individualized medicine and a more efficient and impactful health care system, we need to start seriously investigating one of the basic aspects of an individual's genome, biological sex. Only then can we truly begin to adequately begin the long process of developing individualized medicine for patients.

\section{Acknowledgements}

Thank you to the many faculty, staff, and students at the Exercise Science Research Center for their consistent support of our research.

Availability of data and material

Not applicable.

\section{Authors' contributions}

MER and NPG wrote and edited the manuscript and give final permission for publication.

\section{Funding}

This work was funded by was funded by the National Institutes of Health, Award number: R15 AR069913/AR/NIAMS.
Ethics approval and consent to participate

Not applicable.

\section{Consent for publication}

Not applicable.

\section{Competing interests}

The authors have no completing interests to declare.

Received: 24 July 2019 Accepted: 16 August 2019

Published online: 28 August 2019

\section{References}

1. Carson JA, Manolagas SC. Effects of sex steroids on bones and muscles: similarities, parallels, and putative interactions in health and disease. Bone. 2015;80:67-78.

2. Leitner LM, Wilson RJ, Yan Z, Godecke A. Reactive oxygen species/nitric oxide mediated inter-organ communication in skeletal muscle wasting diseases. Antioxid Redox Signal. 2017;26(13):700-17.

3. Evans WJ. Skeletal muscle loss: cachexia, sarcopenia, and inactivity. Am J Clin Nutr. 2010;91(4):1123s-7s.

4. Ali NA, O'Brien JM Jr, Hoffmann SP, Phillips G, Garland A, Finley JC, et al. Acquired weakness, handgrip strength, and mortality in critically ill patients. Am J Respir Crit Care Med. 2008;178(3):261-8.

5. Sharshar T, Bastuji-Garin S, Stevens RD, Durand MC, Malissin I, Rodriguez P, et al. Presence and severity of intensive care unit-acquired paresis at time of awakening are associated with increased intensive care unit and hospital mortality. Crit Care Med. 2009:37(12):3047-53.

6. Hermans G, Van Mechelen H, Clerckx B, Vanhullebusch T, Mesotten D, Wilmer $A$, et al. Acute outcomes and 1-year mortality of intensive care unit-acquired weakness. A cohort study and propensity-matched analysis. Am J Respir Crit Care Med. 2014;190(4):410-20.

7. Mueller N, Murthy S, Tainter CR, Lee J, Richard K, Fintelmann FJ, et al. Can sarcopenia quantified by ultrasound of the rectus femoris muscle predict adverse outcome of surgical intensive care unit patients and frailty? A Prospective. Observational Cohort Study. Ann Surg. 2016;264(6):1116-24.

8. De Jonghe B, Sharshar T, Lefaucheur JP, Authier FJ, Durand-Zaleski I, Boussarsar $\mathrm{M}$, et al. Paresis acquired in the intensive care unit: a prospective multicenter study. Jama. 2002;288(22):2859-67.

9. Lipes J, Mardini L, Jayaraman D. Sex and mortality of hospitalized adults after admission to an intensive care unit. Am J Crit Care. 2013;22(4):314-9.

10. Morales MG, Abrigo J, Acuna MJ, Santos RA, Bader M, Brandan E, et al. Angiotensin-(1-7) attenuates disuse skeletal muscle atrophy in mice via its receptor. Mas. Dis Model Mech. 2016;9(4):441-9.

11. Fisher AG, Seaborne RA, Hughes TM, Gutteridge A, Stewart C, Coulson JM, et al. Transcriptomic and epigenetic regulation of disuse atrophy and the return to activity in skeletal muscle. Faseb J. 2017;31(12):5268-82.

12. Cannavino J, Brocca L, Sandri M, Bottinelli R, Pellegrino MA. PGC1-alpha over-expression prevents metabolic alterations and soleus muscle atrophy in hindlimb unloaded mice. J Physiol. 2014;592(20):4575-89.

13. Brocca L, Pellegrino MA, Desaphy JF, Pierno S, Camerino DC, Bottinelli $R$. Is oxidative stress a cause or consequence of disuse muscle atrophy in mice? A proteomic approach in hindlimb-unloaded mice. Exp Physiol. 2010;95(2):331-50.

14. Brocca L, Cannavino J, Coletto L, Biolo G, Sandri M, Bottinelli R, et al. The time course of the adaptations of human muscle proteome to bed rest and the underlying mechanisms. J Physiol. 2012;590(20):5211-30.

15. Alibegovic AC, Sonne MP, Hojbjerre L, Bork-Jensen J, Jacobsen S, Nilsson E, et al. Insulin resistance induced by physical inactivity is associated with multiple transcriptional changes in skeletal muscle in young men. Am J Physiol Endocrinol Metab. 2010;299(5):E752-63.

16. Lawler JM, Song W, Demaree SR. Hindlimb unloading increases oxidative stress and disrupts antioxidant capacity in skeletal muscle. Free Radic Biol Med. 2003;35(1):9-16.

17. Kondo H, Miura M, Itokawa Y. Antioxidant enzyme systems in skeletal muscle atrophied by immobilization. Pflugers Arch. 1993:422(4):404-6.

18. Kondo H, Nakagaki I, Sasaki S, Hori S, and Itokawa Y. Mechanism of oxidative stress in skeletal muscle atrophied by immobilization. Am J Physiol. 1993;265(6 Pt 1):E839-844. 
19. Kondo H, Miura M, Kodama J, Ahmed SM, Itokawa Y. Role of iron in oxidative stress in skeletal muscle atrophied by immobilization. Pflugers Arch. 1992:421(2-3):295-7.

20. Servais S, Letexier D, Favier R, Duchamp C, Desplanches D. Prevention of unloading-induced atrophy by vitamin E supplementation: links between oxidative stress and soleus muscle proteolysis? Free Radic Biol Med. 2007; 42(5):627-35.

21. Kessler RC. Epidemiology of women and depression. J Affect Disord. 2003; 74(1):5-13.

22. Van de Velde S, Bracke P, Levecque K. Gender differences in depression in 23 European countries. Cross-national variation in the gender gap in depression. Soc Sci Med. 2010;71(2):305-13.

23. Wang $H$, Hai S, Liu Y, Dong B. Skeletal muscle mass as a mortality predictor among nonagenarians and centenarians: a prospective cohort study. Sci Rep. 2019;9(1):2420.

24. Mauvais-Jarvis F. Sex differences in metabolic homeostasis, diabetes, and obesity. Biol Sex Differ. 2015;6:14

25. Palmer BF, Clegg DJ. The sexual dimorphism of obesity. Mol Cell Endocrinol. 2015;402:113-9.

26. Anderson LJ, Liu H, Garcia JM. Sex differences in muscle wasting. Adv Exp Med Biol. 2017;1043:153-97.

27. Siegel RL, Miller KD, Jemal A. Colorectal cancer mortality rates in adults aged 20 to 54 years in the United States, 1970-2014. Jama. 2017;318(6):5724

28. Mokdad AH, Dwyer-Lindgren L, Fitzmaurice C, Stubbs RW, Bertozzi-Villa A, Morozoff C, et al. Trends and patterns of disparities in cancer mortality among US counties, 1980-2014. Jama. 2017;317(4):388-406.

29. Assi M, Derbre F, Lefeuvre-Orfila L, Rebillard A. Antioxidant supplementation accelerates cachexia development by promoting tumor growth in C26 tumor-bearing mice. Free Radic Biol Med. 2016;91:204-14.

30. Yamashita AS, das Neves RX, Rosa-Neto JC, Lira FD, Batista ML Jr, Alcantara PS, et al. White adipose tissue IFN-gamma expression and signalling along the progression of rodent cancer cachexia. Cytokine. 2017;89:122-6.

31. Neves RX, Rosa-Neto JC, Yamashita AS, Matos-Neto EM, Riccardi DM, Lira FS, et al. White adipose tissue cells and the progression of cachexia: inflammatory pathways. J Cachexia Sarcopenia Muscle. 2016;7(2):193-203.

32. Talbert EE, Metzger GA, He WA, Guttridge DC. Modeling human cancer cachexia in colon 26 tumor-bearing adult mice. J Cachexia Sarcopenia Muscle. 2014;5(4):321-8.

33. Gao Y, Arfat Y, Wang H, Goswami N. Muscle Atrophy Induced by Mechanical unloading: mechanisms and potental countermeasurs. Front Physiol. 2018;9:235.

34. Mauvais-Jarvis F. Sex differences in metabolic homeostasis, diabetes, and obesity. Biol Sex Differ. 2015;6.

35. Callahan DM, Bedrin NG, Subramanian M, Berking J, Ades PA, Toth MJ, et al. Age-related structural alterations in human skeletal muscle fibers and mitochondria are sex specific: relationship to single-fiber function. J Appl Physiol (1985). 2014;116(12):1582-1592.

36. Haizlip KM, Harrison BC, Leinwand LA. Sex-based differences in skeletal muscle kinetics and fiber-type composition. Physiology (Bethesda). 2015; 30(1):30-9.

37. Wang Y, Pessin JE. Mechanisms for fiber-type specificity of skeletal muscle atrophy. Curr Opin Clin Nutr Metab Care. 2013;16(3):243-50.

38. Talbot J, Maves L. Skeletal muscle fiber type: using insights from muscle developmental biology to dissect targets for susceptibility and resistance to muscle disease. Wiley Interdiscip Rev Dev Biol. 2016;5(4):518-34.

39. Picard M, Ritchie D, Thomas MM, Wright KJ, Hepple RT. Alterations in intrinsic mitochondrial function with aging are fiber type-specific and do not explain differential atrophy between muscles. Aging Cell. 2011;10(6):1047-55.

40. Brown JL, Rosa-Caldwell ME, Lee DE, Blackwell TA, Brown LA, Perry RA, et al. Mitochondrial degeneration precedes the development of muscle atrophy in progression of cancer cachexia in tumour-bearing mice. J Cachexia Sarcopenia Muscle. 2017:8(6):926-38.

41. Thomason DB, Herrick RE, Surdyka D, Baldwin KM. Time course of soleus muscle myosin expression during hindlimb suspension and recovery. J Appl Physiol (1985). 1987;63(1):130-137.

42. Angelini C, Tasca E, Nascimbeni AC, Fanin M. Muscle fatigue, nNOS and muscle fiber atrophy in limb girdle muscular dystrophy. Acta Myol. 2014; 33(3):119-26.

43. Baracos VE, Reiman T, Mourtzakis M, Gioulbasanis I, Antoun S. Body composition in patients with non-small cell lung cancer: a contemporary view of cancer cachexia with the use of computed tomography image analysis. Am J Clin Nutr. 2010;91(4):1133s-7s.

44. Hendifar A, Yang D, Lenz F, Lurje G, Pohl A, Lenz C, et al. Gender disparities in metastatic colorectal cancer survival. Clin Cancer Res. 2009;15(20):6391-7.

45. Wallengren O, Iresjo BM, Lundholm K, Bosaeus I. Loss of muscle mass in the end of life in patients with advanced cancer. Support Care Cancer. 2015; 23(1):79-86.

46. Callahan DM, Tourville TW, Miller MS, Hackett SB, Sharma H, Cruickshank NC, et al. Chronic disuse and skeletal muscle structure in older adults: sexspecific differences and relationships to contractile function. Am J Physiol Cell Physiols. 2015;308(11):C932-43.

47. Callahan DM, Miller MS, Sweeny AP, Tourville TW, Slauterbeck JR, Savage PD, et al. Muscle disuse alters skeletal muscle contractile function at the molecular and cellular levels in older adult humans in a sex-specific manner J Physiol. 2014;592(20):4555-73.

48. Cosper PF, Leinwand LA. Cancer causes cardiac atrophy and autophagy in a sexually dimorphic manner. Cancer Res. 2011;71(5):1710-20.

49. Yoshihara T, Natsume T, Tsuzuki T, Chang SW, Kakigi R, Sugiura T, et al. Sex differences in forkhead box O3a signaling response to hindlimb unloading in rat soleus muscle. J Physiol Sci. 2019;69(2):235-44.

50. Hodson N, Philp A. The importance of mTOR trafficking for human skeletal muscle translational control. Exerc Sport Sci Rev. 2019;47(1):46-53.

51. Dreyer HC, Fujita S, Glynn EL, Drummond MJ, Volpi E, Rasmussen BB. Resistance exercise increases leg muscle protein synthesis and mTOR signalling independent of sex. Acta Physiol (Oxf). 2010;199(1):71-81.

52. West DW, Burd NA, Churchward-Venne TA, Camera DM, Mitchell CJ, Baker SK, et al. Sex-based comparisons of myofibrillar protein synthesis after resistance exercise in the fed state. J Appl Physiol (1985). 2012; 112(11):1805-1813.

53. Volpi E, Lucidi P, Bolli GB, Santeusanio F, De Feo P. Gender differences in basal protein kinetics in young adults. J Clin Endocrinol Metab. 1998; 83(12):4363-7.

54. Fujita S, Rasmussen BB, Bell JA, Cadenas JG, Volpi E. Basal muscle intracellular amino acid kinetics in women and men. Am J Physiol Endocrinol Metab. 2007;292(1):E77-83.

55. Smith Gl, Atherton P, Reeds DN, Mohammed BS, Jaffery H, Rankin D, et al. No major sex differences in muscle protein synthesis rates in the postabsorptive state and during hyperinsulinemia-hyperaminoacidemia in middle-aged adults. J Appl Physiol (1985). 2009;107(4):1308-1315.

56. Horstman AMH, Kouw IWK, van Dijk JW, Hamer HM, Groen BBL, van Kranenburg J, et al. The muscle protein synthetic response to whey protein ingestion is greater in middle-aged women compared with men. J Clin Endocrinol Metab. 2019;104(4):994-1004.

57. Scalzo RL, Peltonen GL, Binns SE, Shankaran M, Giordano GR, Hartley DA, et al. Greater muscle protein synthesis and mitochondrial biogenesis in males compared with females during sprint interval training. Faseb J. 2014;28(6): 2705-14.

58. Murach KA, Fry CS, Kirby TJ, Jackson JR, Lee JD, White SH, et al. Starring or Supporting Role? Satellite Cells and Skeletal Muscle Fiber Size Regulation. Physiology (Bethesda). 2018;33(1):26-38

59. Manzano R, Toivonen JM, Calvo AC, Miana-Mena FJ, Zaragoza P, Munoz MJ, et al. Sex, fiber-type, and age dependent in vitro proliferation of mouse muscle satellite cells. J Cell Biochem. 2011:112(10):2825-36.

60. Song Y, McFarland DC, Velleman SG. Growth and sex effects on the expression of syndecan-4 and glypican-1 in turkey myogenic satellite cell populations. Mol Cell Biochem. 2013;378(1-2):65-72.

61. Neal A, Boldrin L, Morgan JE. The satellite cell in male and female, developing and adult mouse muscle: distinct stem cells for growth and regeneration. PLoS One. 2012;7(5):e37950.

62. Joubert $Y$, Tobin $C$. Testosterone treatment results in quiescent satellite cells being activated and recruited into cell cycle in rat levator ani muscle. Dev Biol. 1995;169(1):286-94.

63. Lee DM, Bajracharya P, Lee EJ, Kim JE, Lee HJ, Chun T, et al. Effects of gender-specific adult bovine serum on myogenic satellite cell proliferation, differentiation and lipid accumulation. In Vitro Cell Dev Biol Anim. 2011; 47(7):438-44

64. Nnodim JO. Testosterone mediates satellite cell activation in denervated rat levator ani muscle. Anat Rec. 2001;263(1):19-24.

65. Mulvaney DR, Marple DN, Merkel RA. Proliferation of skeletal muscle satellite cells after castration and administration of testosterone propionate. Proc Soc Exp Biol Med. 1988;188(1):40-5. 
66. Dalbo VJ, Roberts MD, Mobley CB, Ballmann C, Kephart WC, Fox CD, et al. Testosterone and trenbolone enanthate increase mature myostatin protein expression despite increasing skeletal muscle hypertrophy and satellite cell number in rodent muscle. Andrologia. 2017;49(3).

67. Egner IM, Bruusgaard JC, Eftestol E, Gundersen K. A cellular memory mechanism aids overload hypertrophy in muscle long after an episodic exposure to anabolic steroids. J Physiol. 2013;591(24):6221-30.

68. Egner IM, Bruusgaard JC, Gundersen K. Satellite cell depletion prevents fiber hypertrophy in skeletal muscle. Development. 2016;143(16):2898-906.

69. McCarthy JJ, Dupont-Versteegden EE, Fry CS, Murach KA, Peterson CA. Methodological issues limit interpretation of negative effects of satellite cell depletion on adult muscle hypertrophy. Development. 2017;144(8):1363-5.

70. McCarthy JJ, Mula J, Miyazaki M, Erfani R, Garrison K, Farooqui AB, et al. Effective fiber hypertrophy in satellite cell-depleted skeletal muscle. Development. 2011;138(17):3657-66.

71. Murach KA, Englund DA, Dupont-Versteegden EE, McCarthy JJ, Peterson CA. Myonuclear domain flexibility challenges rigid assumptions on satellite cell contribution to skeletal muscle fiber hypertrophy. Front Physiol. 2018;9:635.

72. Sandri M. Protein breakdown in muscle wasting: role of autophagy-lysosome and ubiquitin-proteasome综放. Int J Biochem Cell Biol. 2013;45(10):2121-9.

73. Brooks NE, Myburgh KH. Skeletal muscle wasting with disuse atrophy is multi-dimensional: the response and interaction of myonuclei, satellite cells and signaling pathways. Front Physiol. 2014;5.

74. Gomes MD, Lecker SH, Jagoe RT, Navon A, Goldberg AL. Atrogin-1, a muscle-specific F-box protein highly expressed during muscle atrophy. Proc Natl Acad Sci U S A. 2001;98(25):14440-5.

75. Lecker SH, Jagoe RT, Gilbert A, Gomes M, Baracos V, Bailey J, et al. Multiple types of skeletal muscle atrophy involve a common program of changes in gene expression. Faseb J. 2004;18(1):39-51.

76. Klionsky DJ, Abdelmohsen K, Abe A, Abedin MJ, Abeliovich H, Acevedo Arozena A, et al. Guidelines for the use and interpretation of assays for monitoring autophagy (3rd edition). Autophagy. 2016;12(1):1-222.

77. Wesselborg S, Stork B. Autophagy signal transduction by ATG proteins: from hierarchies to networks. Cell Mol Life Sci. 2015;72:4721-57.

78. Shu Y, Xia J, Yu Q, Wang G, Zhang J, He J, et al. Integrated analysis of mRNA and miRNA expression profiles reveals muscle growth differences between adult female and male Chinese concave-eared frogs (Odorrana tormota). Gene. 2018:678:241-51.

79. Ogawa M, Kitano T, Kawata N, Sugihira T, Kitakaze T, Harada N, et al. Daidzein down-regulates ubiquitin-specific protease 19 expression through estrogen receptor beta and increases skeletal muscle mass in young female mice. J Nutr Biochem. 2017;49:63-70.

80. Ogawa M, Kitakaze T, Harada N, Yamaji R. Female-specific regulation of skeletal muscle mass by USP19 in young mice. J Endocrinol. 2015; 225(3):135-45

81. Olivan S, Calvo AC, Manzano R, Zaragoza P, Osta R. Sex differences in constitutive autophagy. Biomed Res Int. 2014;2014:652817.

82. Piekarski A, Khaldi S, Greene E, Lassiter K, Mason JG, Anthony N, et al. Tissue distribution, gender- and genotype-dependent expression of autophagy-related genes in avian species. PLoS One. 2014;9(11):e112449.

83. Sacheck JM, Hyatt JP, Raffaello A, Jagoe RT, Roy RR, Edgerton VR, et al. Rapid disuse and denervation atrophy involve transcriptional changes similar to those of muscle wasting during systemic diseases. Faseb J. 2007;21(1):140-55

84. Stevenson EJ, Giresi PG, Koncarevic A, Kandarian SC. Global analysis of gene expression patterns during disuse atrophy in rat skeletal muscle. J Physiol. 2003:551(Pt 1):33-48.

85. Jang J, Park J, Chang H, Lim K. I-Carnitine supplement reduces skeletal muscle atrophy induced by prolonged hindlimb suspension in rats. Appl Physiol Nutr Metab. 2016;41(12):1240-7.

86. Jamart C, Raymackers JM, Li An G, Deldicque L, Francaux M. Prevention of muscle disuse atrophy by MG132 proteasome inhibitor. Muscle Nerve. 2011; 43(5):708-16.

87. Zhang P, Li W, Liu H, Li J, Wang J, Li Y, et al. Dystrophin involved in the susceptibility of slow muscles to hindlimb unloading via concomitant activation of TGF-beta1/Smad3 signaling and ubiquitin-proteasome degradation in mice. Cell Biochem Biophys. 2014;70(2):1057-67.

88. Jones SW, Hill RJ, Krasney PA, O'Conner B, Peirce N, Greenhaff PL. Disuse atrophy and exercise rehabilitation in humans profoundly affects the expression of genes associated with the regulation of skeletal muscle mass. Faseb J. 2004;18(9):1025-7.
89. Maki T, Yamamoto D, Nakanishi S, lida K, Iguchi G, Takahashi Y, et al Branched-chain amino acids reduce hindlimb suspension-induced muscle atrophy and protein levels of atrogin-1 and MuRF1 in rats. Nutr Res. 2012; 32(9):676-83.

90. Bialek P, Morris C, Parkington J, St Andre M, Owens J, Yaworsky P, et al. Distinct protein degradation profiles are induced by different disuse models of skeletal muscle atrophy. Physiol Genomics. 2011;43(19):1075-86.

91. Talbert EE, Smuder AJ, Min K, Kwon OS, Szeto HH, Powers SK. Immobilization-induced activation of key proteolytic systems in skeletal muscles is prevented by a mitochondria-targeted antioxidant. J Appl Physiol (1985). 2013;115(4):529-538.

92. Kang C, Ji LL. PGC-1alpha overexpression via local transfection attenuates mitophagy pathway in muscle disuse atrophy. Free Radic Biol Med. 2016;93:32-40.

93. Levine S, Biswas C, Dierov J, Barsotti R, Shrager JB, Nguyen T, et al. Increased proteolysis, myosin depletion, and atrophic AKT-FOXO signaling in human diaphragm disuse. Am J Respir Crit Care Med. 2011;183(4):483-90.

94. Hussain SN, Mofarrahi M, Sigala I, Kim HC, Vassilakopoulos T, Maltais F, et al. Mechanical ventilation-induced diaphragm disuse in humans triggers autophagy. Am J Respir Crit Care Med. 2010;182(11):1377-86.

95. Reardon KA, Davis J, Kapsa RM, Choong P, Byrne E. Myostatin, insulin-like growth factor-1, and leukemia inhibitory factor mRNAs are upregulated in chronic human disuse muscle atrophy. Muscle Nerve. 2001;24(7):893-9.

96. Lach-Trifilieff E, Minetti GC, Sheppard K, Ibebunjo C, Feige JN, Hartmann $\mathrm{S}$, et al. An antibody blocking activin type II receptors induces strong skeletal muscle hypertrophy and protects from atrophy. Mol Cell Biol. 2014;34(4):606-18.

97. Lee SJ, Huynh TV, Lee YS, Sebald SM, Wilcox-Adelman SA, Iwamori N, et al. Role of satellite cells versus myofibers in muscle hypertrophy induced by inhibition of the myostatin/activin signaling pathway. Proc Natl Acad Sci U S A. 1092012. p. E2353-E2360.

98. Gentry BA, Ferreira JA, Phillips CL, Brown M. Hindlimb skeletal muscle function in myostatin-deficient mice. Muscle Nerve. 2011;43(1):49-57.

99. Dubois V, Laurent MR, Sinnesael M, Cielen N, Helsen C, Clinckemalie L, et al. A satellite cell-specific knockout of the androgen receptor reveals myostatin as a direct androgen target in skeletal muscle. Faseb J. 2014;28(7):2979-94.

100. Ma D, Gao P, Qian L, Wang Q, Cai C, Jiang S, et al. Over-expression of porcine myostatin missense mutant leads to a gender difference in skeletal muscle growth between transgenic male and female mice. Int J Mol Sci. 2015;16(8):20020-32

101. Qiao S, Nordstrom K, Muijs L, Gasparoni G, Tierling S, Krause E, et al. Molecular plasticity of male and female murine gonadotropes revealed by mRNA sequencing. Endocrinology. 2016;157(3):1082-93.

102. White JP, Baltgalvis KA, Sato S, Wilson LB, Carson JA. Effect of nandrolone decanoate administration on recovery from bupivacaine-induced muscle injury. J Appl Physiol. 1985;1072009:1420-30.

103. Spangenburg EE, Geiger PC, Leinwand LA, Lowe DA. Regulation of physiological and metabolic function of muscle by female sex steroids. Med Sci Sports Exerc. 2012;44(9):1653-62.

104. McClung JM, Davis JM, Wilson MA, Goldsmith EC, Carson JA. Estrogen status and skeletal muscle recovery from disuse atrophy. J Appl Physiol (1985). 2006;100(6):2012-2023.

105. Basaria S, Coviello AD, Travison TG, Storer TW, Farwell WR, Jette AM, et al. Adverse events associated with testosterone administration. N Engl J Med. 2010;363(2):109-22.

106. Normal Laboratory Values (for adults) - ESAP 2015 Laboratory Reference Ranges.pdf 2018 [Available from: https://education.endocrine.org/system/ files/ESAP\%202015\%20Laboratory\%20Reference\%20Ranges.pdf.

107. Basualto-Alarcon C, Jorquera G, Altamirano F, Jaimovich E, Estrada M. Testosterone signals through $\mathrm{mTOR}$ and androgen receptor to induce muscle hypertrophy. Med Sci Sports Exerc. 2013;45(9):1712-20.

108. Schiaffino S, Dyar KA, Ciciliot S, Blaauw B, Sandri M. Mechanisms regulating skeletal muscle growth and atrophy. Febs J. 2013;280(17):4294-314.

109. Altuwaijri S, Lee DK, Chuang KH, Ting HJ, Yang Z, Xu Q, et al. Androgen receptor regulates expression of skeletal muscle-specific proteins and muscle cell types. Endocrine. 2004;25(1):27-32.

110. Sinha I, Sinha-Hikim AP, Wagers AJ, Sinha-Hikim I. Testosterone is essential for skeletal muscle growth in aged mice in a heterochronic parabiosis model. Cell Tissue Res. 2014;357(3):815-21.

111. McHale MJ, Sarwar ZU, Cardenas DP, Porter L, Salinas AS, Michalek JE, et al. Increased fat deposition in injured skeletal muscle is regulated 
by sex-specific hormones. Am J Physiol Regul Integr Comp Physiol. 2012;302(3):R331-9.

112. Bhasin S, Storer TW, Berman N, Yarasheski KE, Clevenger B, Phillips J, et al. Testosterone replacement increases fat-free mass and muscle size in hypogonadal men. J Clin Endocrinol Metab. 1997;82(2):407-13.

113. Smith Gl, Yoshino J, Reeds DN, Bradley D, Burrows RE, Heisey HD, et al. Testosterone and progesterone, but not estradiol, stimulate muscle protein synthesis in postmenopausal women. J Clin Endocrinol Metab. 2014;99(1):256-65.

114. Mitchell CJ, Churchward-Venne TA, Bellamy L, Parise G, Baker SK, Phillips SM. Muscular and systemic correlates of resistance training-induced muscle hypertrophy. PLoS One. 2013;8(10):e78636.

115. West DWD, Phillips SM. Associations of exercise-induced hormone profiles and gains in strength and hypertrophy in a large cohort after weight training. Eur J Appl Physiol. 1122012:2693-702.

116. Swift-Gallant A, Monks DA. Androgen receptor expression in satellite cells of the neonatal levator ani of the rat. Dev Neurobiol. 2013;73(6):448-54.

117. Burney BO, Hayes TG, Smiechowska J, Cardwell G, Papusha V, Bhargava P, et al. Low testosterone levels and increased inflammatory markers in patients with cancer and relationship with cachexia. J Clin Endocrinol Metab. 2012; 97(5):E700-9.

118. White JP, Puppa MJ, Narsale A, Carson JA. Characterization of the male ApcMin/+ mouse as a hypogonadism model related to cancer cachexia. Biol Open. 2013;2(12):1346-53.

119. Moore PD, Gorgey AS, Wade RC, Khalil RE, Lavis TD, Khan R, et al. Neuromuscular electrical stimulation and testosterone did not influence heterotopic ossification size after spinal cord injury: A case series. World J Clin Cases. 2016;4(7):172-6.

120. Bauman WA, Cirnigliaro CM, La Fountaine MF, Jensen AM, Wecht JM, Kirshblum SC, et al. A small-scale clinical trial to determine the safety and efficacy of testosterone replacement therapy in hypogonadal men with spinal cord injury. Horm Metab Res. 2011;43(8):574-9.

121. Zhao W, Pan J, Zhao Z, Wu Y, Bauman WA, Cardozo CP. Testosterone protects against dexamethasone-induced muscle atrophy, protein degradation and MAFbx upregulation. J Steroid Biochem Mol Biol. 2008; 110(1-2):125-9.

122. St George A, Bauman A, Johnston A, Farrell G, Chey T, George J. Independent effects of physical activity in patients with nonalcoholic fatty liver disease. Hepatology. 2009;50(1):68-76.

123. Dalton JT, Taylor RP, Mohler ML, Steiner MS. Selective androgen receptor modulators for the prevention and treatment of muscle wasting associated with cancer. Curr Opin Support Palliat Care. 2013;7(4):345-51.

124. Wright TJ, Dillon EL, Durham WJ, Chamberlain A, Randolph KM, Danesi C, et al. A randomized trial of adjunct testosterone for cancer-related muscle loss in men and women. J Cachexia Sarcopenia Muscle. 2018:9(3):482-96.

125. Harjola V, Jankala H, Harkonen M. Myosin heavy chain mRNA and protein distribution in immobilized rat skeletal muscle are not affected by testosterone status. Acta Physiol Scand. 2000;169(4):277-82.

126. De Naeyer H, Lamon S, Russell AP, Everaert I, De Spaey A, Jamart C, et al. Effects of tail suspension on serum testosterone and molecular targets regulating muscle mass. Muscle Nerve. 2015;52(2):278-88.

127. Reed BG, Carr BR. The Normal Menstrual Cycle and the Control of Ovulation. In: Endotext. South Dartmouth: MDText.com, Inc.; 2018

128. Smith MS, Freeman ME, Neill JD. The control of progesterone secretion during the estrous cycle and early pseudopregnancy in the rat: prolactin, gonadotropin and steroid levels associated with rescue of the corpus luteum of pseudopregnancy. Endocrinology. 1975;96(1):219-26.

129. Kramer PR, Bellinger LL. The effects of cycling levels of 17ß-estradiol and progesterone on the magnitude of temporomandibular joint-induced nociception. Endocrinology. 2009;150(8):3680-9.

130. Butcher RL, Collins WE, Fugo NW. Plasma concentration of LH, FSH, prolactin, progesterone and estradiol-17beta throughout the 4-day estrous cycle of the rat. Endocrinology. 1974;94(6):1704-8.

131. Butcher RL, Inskeep EK, Pope RS. Plasma concentrations of estradiol produced with two delivery systems in ovariectomized rats. Proc Soc Exp Biol Med. 1978;158(3):475-7.

132. Kalra SP, Kalra PS. Temporal interrelationships among circulating levels of estradiol, progesterone and $\mathrm{LH}$ during the rat estrous cycle: effects of exogenous progesterone. Endocrinology. 1974;95(6):1711-8.

133. Devries MC, Hamadeh MJ, Phillips SM, Tarnopolsky MA. Menstrual cycle phase and sex influence muscle glycogen utilization and glucose turnover during moderate-intensity endurance exercise. Am J Physiol Regul Integr Comp Physiol. 2006;291(4):R1120-8

134. Parr MK, Zhao P, Haupt O, Ngueu ST, Hengevoss J, Fritzemeier KH, et al. Estrogen receptor beta is involved in skeletal muscle hypertrophy induced by the phytoecdysteroid ecdysterone. Mol Nutr Food Res. 2014;58(9):1861-72.

135. Kamanga-Sollo E, White ME, Weber WJ, Dayton WR. Role of estrogen receptor-alpha (ESR1) and the type 1 insulin-like growth factor receptor (IGFR1) in estradiol-stimulated proliferation of cultured bovine satellite cells. Domest Anim Endocrinol. 2013:44(1):36-45.

136. Velarde MC. Mitochondrial and sex steroid hormone crosstalk during aging. Longev Healthspan. 2014;3(1):2

137. Murphy E, Steenbergen C. Gender-based differences in mechanisms of protection in myocardial ischemia-reperfusion injury. Cardiovasc Res. 2007; 75(3):478-86.

138. Velarde MC. Pleiotropic actions of estrogen: a mitochondrial matter. Physiol Genomics. 2013;45(3):106-9.

139. Naugler WE, Sakurai T, Kim S, Maeda S, Kim K, Elsharkawy AM, et al. Gender disparity in liver cancer due to sex differences in MyD88-dependent IL-6 production. Science. 2007;317(5834):121-4.

140. Hetzler KL, Hardee JP, LaVoie HA, Murphy EA, Carson JA. Ovarian function's role during cancer cachexia progression in the female mouse. Am J Physiol Endocrinol Metab. 2017;312(5):E447-e59.

141. Teveroni E, Pellegrino M, Sacconi S, Calandra P, Cascino I, Farioli-Vecchioli S, et al. Estrogens enhance myoblast differentiation in facioscapulohumeral muscular dystrophy by antagonizing DUX4 activity. J Clin Invest. 2017; 127(4):1531-45.

142. Matsakas A, Yadav V, Lorca S, Narkar V. Muscle ERRgamma mitigates Duchenne muscular dystrophy via metabolic and angiogenic reprogramming. Faseb J. 2013;27(10):4004-16.

143. Dorchies OM, Reutenauer-Patte J, Dahmane E, Ismail HM, Petermann O. Patthey- Vuadens $\mathrm{O}$, et al. The anticancer drug tamoxifen counteracts the pathology in a mouse model of duchenne muscular dystrophy. Am J Pathol. 2013;182(2):485-504.

144. Gayi E, Neff LA, Ismail HM, Ruegg UT, Scapozza L, Dorchies OM. Repurposing the selective oestrogen receptor modulator tamoxifen for the treatment of duchenne muscular dystrophy. Chimia (Aarau). 2018;72(4):238-40.

145. Huss JM, Garbacz WG, Xie W. Constitutive activities of estrogen-related receptors: Transcriptional regulation of metabolism by the ERR pathways in health and disease. Biochim Biophys Acta. 2015;1852(9):1912-27.

146. Kararigas G, Bito V, Tinel H, Becher E, Baczko I, Knosalla C, et al. Transcriptome characterization of estrogen-treated human myocardium identifies myosin regulatory light chain interacting protein as a sex-specific element influencing contractile function. J Am Coll Cardiol. 2012:59(4):410-7.

147. Kawano S, Kanda K, Ohmori S, Izumi R, Yasukawa K, Murata Y, et al. Effect of estrogen on the development of disuse atrophy of bone and muscle induced by tail-supension in rats. Environ Med. 1997;41(2):89-92.

148. Mukai R, Horikawa H, Lin PY, Tsukumo N, Nikawa T, Kawamura T, et al. 8Prenylnaringenin promotes recovery from immobilization-induced disuse muscle atrophy through activation of the Akt phosphorylation pathway in mice. Am J Physiol Regul Integr Comp Physiol. 2016;311 (6):R1022-r31.

149. Mukai R, Horikawa H, Fujikura Y, Kawamura T, Nemoto H, Nikawa T, et al. Prevention of disuse muscle atrophy by dietary ingestion of 8prenylnaringenin in denervated mice. PLoS One. 2012;7(9):e45048,

150. Sugiura T, Ito N, Goto K, Naito H, Yoshioka T, Powers SK. Estrogen administration attenuates immobilization-induced skeletal muscle atrophy in male rats. J Physiol Sci. 2006;56(6):393-9.

151. Ohmori S, Kanda K, Kawano S, Kambe F, Seo H. Changes in calcium, PTH and 1,25(OH)2 vitamin D3 during tail-suspension in ovariectomized rats: effects of estrogen administration. Environ Med. 2000:44(2):75-8.

152. Kane DA, Lin CT, Anderson EJ, Kwak HB, Cox JH, Brophy PM, et al. Progesterone increases skeletal muscle mitochondrial $\mathrm{H} 2 \mathrm{O} 2$ emission in nonmenopausal women. Am J Physiol Endocrinol Metab. 2011; 300(3):E528-35.

153. Mankowski RT, Anton SD, Buford TW, Leeuwenburgh C. Dietary antioxidants as modifiers of physiologic adaptations to exercise. Med Sci Sports Exerc. 2015:47(9):1857-68.

154. Dai Q, Shah AA, Garde RV, Yonish BA, Zhang L, Medvitz NA, et al. A truncated progesterone receptor (PR-M) localizes to the mitochondrion and controls cellular respiration. Mol Endocrinol. 2013;27(5):741-53.

155. Price TM, Dai Q. The Role of a Mitochondrial progesterone receptor (PR-M) in progesterone action. Semin Reprod Med. 2015;33(3):185-94. 
156. Bottje W, Kong BW, Reverter A, Waardenberg AJ, Lassiter K, Hudson NJ. Progesterone signalling in broiler skeletal muscle is associated with divergent feed efficiency. BMC Syst Biol. 2017;11(1):29.

157. De Jager N, Hudson NJ, Reverter A, Barnard R, Cafe LM, Greenwood PL, et al. Gene expression phenotypes for lipid metabolism and intramuscular fat in skeletal muscle of cattle. J Anim Sci. 2013;91(3):1112-28.

158. Goldstein J, Sites CK, Toth MJ. Progesterone stimulates cardiac muscle protein synthesis via receptor-dependent pathway. Fertil Steril. 2004; 82(2):430-6.

159. Dossat AM, Wright KN, Strong CE, Kabbaj M. Behavioral and biochemical sensitivity to low doses of ketamine: Influence of estrous cycle in C57BL/6 mice. Neuropharmacology. 2018;130:30-41.

160. Bigos KL, Pollock BG, Stankevich BA, Bies RR. Sex differences in the pharmacokinetics and pharmacodynamics of antidepressants: an updated review. Gend Med. 2009;6(4):522-43.

161. Offner $H$. Neuroimmunoprotective effects of estrogen and derivatives in experimental autoimmune encephalomyelitis: therapeutic implications for multiple sclerosis. J Neurosci Res. 2004;78(5):603-24.

162. Offner $H$, Polanczyk M. A potential role for estrogen in experimental autoimmune encephalomyelitis and multiple sclerosis. Ann N Y Acad Sci. 2006:1089:343-72.

163. You S, Ohmori M, Pena MM, Nassri B, Quiton J, Al-Assad ZA, et al. Developmental abnormalities in multiple proliferative tissues of $\mathrm{Apc}(\mathrm{Min} /+)$ mice. Int J Exp Pathol. 2006;87(3):227-36.

164. Wall BT, Dirks ML, van Loon LJ. Skeletal muscle atrophy during short-term disuse: implications for age-related sarcopenia. Ageing Res Rev. 2013;12(4): 898-906.

165. Montero D, Madsen K, Meinild-Lundby AK, Edin F, Lundby C. Sexual dimorphism of substrate utilization: Differences in skeletal muscle mitochondrial volume density and function. Exp Physiol. 2018;103(6):851-9.

166. McKenzie S, Phillips SM, Carter SL, Lowther S, Gibala MJ, Tarnopolsky MA. Endurance exercise training attenuates leucine oxidation and BCOAD activation during exercise in humans. Am J Physiol Endocrinol Metab. 2000; 278(4):E580-7.

167. Valle A, Guevara R, Garcia-Palmer FJ, Roca P, Oliver J. Sexual dimorphism in liver mitochondrial oxidative capacity is conserved under caloric restriction conditions. Am J Physiol Cell Physiol. 2007;293(4):C1302-8.

168. Colom B, Alcolea MP, Valle A, Oliver J, Roca P, Garcia-Palmer FJ. Skeletal muscle of female rats exhibit higher mitochondrial mass and oxidativephosphorylative capacities compared to males. Cell Physiol Biochem. 2007; 19(1-4):205-12.

169. Justo R, Boada J, Frontera M, Oliver J, Bermudez J, Gianotti M. Gender dimorphism in rat liver mitochondrial oxidative metabolism and biogenesis. Am J Physiol Cell Physiol. 2005;289(2):C372-8.

170. Chweih H, Castilho RF, Figueira TR. Tissue and sex specificities in Ca2+ handling by isolated mitochondria in conditions avoiding the permeability transition. Exp Physiol. 2015;100(9):1073-92.

171. Colom B, Oliver J, Garcia-Palmer FJ. Sexual dimorphism in the alterations of cardiac muscle mitochondrial bioenergetics associated to the ageing process. J Gerontol A Biol Sci Med Sci. 2015;70(11):1360-9.

172. Sharma J, Johnston MV, Hossain MA. Sex differences in mitochondrial biogenesis determine neuronal death and survival in response to oxygen glucose deprivation and reoxygenation. BMC Neurosci. 2014;15:9.

173. Straface E, Vona R, Campesi I, Franconi F. Mitochondria can orchestrate sex differences in cell fate of vascular smooth muscle cells from rats. Biol Sex Differ. 2015;6:34

174. Girten B, Oloff C, Plato P, Eveland E, Merola AJ, Kazarian L. Skeletal muscle antioxidant enzyme levels in rats after simulated weightlessness, exercise and dobutamine. Physiologist. 1989;32(1 Suppl):S59-60.

175. Appell HJ, Duarte JA, Soares JM. Supplementation of vitamin E may attenuate skeletal muscle immobilization atrophy. Int J Sports Med. 1997; 18(3):157-60.

176. Lin J, Wu H, Tarr PT, Zhang CY, Wu Z, Boss O, et al. Transcriptional coactivator PGC-1 alpha drives the formation of slow-twitch muscle fibres. Nature. 2002;418(6899):797-801.

177. Brault JJ, Jespersen JG, Goldberg AL. Peroxisome proliferator-activated receptor gamma coactivator 1alpha or 1 beta overexpression inhibits muscle protein degradation, induction of ubiquitin ligases, and disuse atrophy. J Biol Chem. 2010;285(25):19460-71.

178. Kang C, Ji LL. PGC-1a overexpression via local transfection attenuates mitophagy pathway in muscle disuse atrophy. Free Radic Biol Med. 2015.
179. Rosa-Caldwell ME, Brown JL, Lee DE, Blackwell TA, Turner KW, Brown LA, et al. Autophagy activation, not peroxisome proliferator-activated receptor gamma coactivator 1alpha, may mediate exercise-induced improvements in glucose handling during diet-induced obesity. Exp Physiol. 2017;102(9): 1194-207.

180. Miura S, Kai Y, Ono M, Ezaki O. Overexpression of peroxisome proliferatoractivated receptor gamma coactivator-1alpha down-regulates GLUT4 mRNA in skeletal muscles. J Biol Chem. 2003;278(33):31385-90.

181. Choi CS, Befroy DE, Codella R, Kim S, Reznick RM, Hwang YJ, et al. Paradoxical effects of increased expression of PGC-1alpha on muscle mitochondrial function and insulin-stimulated muscle glucose metabolism. Proc Natl Acad Sci U S A. 2008;105(50):19926-31.

182. Goncalves RL, Quinlan CL, Perevoshchikova IV, Hey-Mogensen M, Brand MD. Sites of superoxide and hydrogen peroxide production by muscle mitochondria assessed ex vivo under conditions mimicking rest and exercise. J Biol Chem. 2015;290(1):209-27.

183. Thompson JR, Swanson SA, Casale GP, Johanning JM, Papoutsi E, Koutakis $P$, et al. Gastrocnemius mitochondrial respiration: are there any differences between men and women? J Surg Res. 2013;185(1):206-11.

184. Grossman A, Oppenheim J, Grondin G, St Jean P, Beaudoin AR. Immunocytochemical localization of the $[3 \mathrm{H}]$ estradiol-binding protein in rat pancreatic acinar cells. Endocrinology. 1989;124(6):2857-66.

185. Noteboom WD, Gorski J. Stereospecific binding of estrogens in the rat uterus. Arch Biochem Biophys. 1965;111(3):559-68.

186. Moats RK 2nd, Ramirez VD. Rapid uptake and binding of estradiol-17beta-6(O-carboxymethyl)oxime:125I-labeled BSA by female rat liver. Biol Reprod. 1998:58(2):531-8.

187. Monje P, Boland R. Subcellular distribution of native estrogen receptor alpha and beta isoforms in rabbit uterus and ovary. J Cell Biochem. 2001; 82(3):467-79.

188. Chen JQ, Delannoy M, Cooke C, Yager JD. Mitochondrial localization of ERalpha and ERbeta in human MCF7 cells. Am J Physiol Endocrinol Metab. 2004:286(6):E1011-22.

189. Cammarata PR, Chu S, Moor A, Wang Z, Yang SH, Simpkins JW. Subcellular distribution of native estrogen receptor alpha and beta subtypes in cultured human lens epithelial cells. Exp Eye Res. 2004;78(4):861-71.

190. Yang SH, Liu R, Perez EJ, Wen Y, Stevens SM Jr, Valencia T, et al. Mitochondrial localization of estrogen receptor beta. Proc Natl Acad Sci U S A. 2004;101(12):4130-5.

191. Gavrilova-Jordan LP, Price TM. Actions of steroids in mitochondria. Semin Reprod Med. 2007;25:154-64.

192. Toda K, Takeda K, Okada T, Akira S, Saibara T, Kaname T, et al. Targeted disruption of the aromatase P450 gene (Cyp19) in mice and their ovarian and uterine responses to 17beta-oestradiol. J Endocrinol. 2001:170(1):99-111.

193. Burris TP, Krishnan V. Estrogen: a mitochondrial energizer that keeps on going. Mol Pharmacol. 2005;68(4):956-8.

194. Ivanova MM, Mazhawidza W, Dougherty SM, Klinge CM. Sex differences in estrogen receptor subcellular location and activity in lung adenocarcinoma cells. Am J Respir Cell Mol Biol. 2010;42(3):320-30.

195. Dougherty SM, Mazhawidza W, Bohn AR, Robinson KA, Mattingly KA, Blankenship KA, et al. Gender difference in the activity but not expression of estrogen receptors $a$ and $\beta$ in human lung adenocarcinoma cells. Endocr Relat Cancer. 2006:13(1):113-34.

196. Solakidi S, Psarra AM, Nikolaropoulos S, Sekeris CE. Estrogen receptors alpha and beta (ERalpha and ERbeta) and androgen receptor (AR) in human sperm: localization of ERbeta and AR in mitochondria of the midpiece. Hum Reprod. 2005;20(12):3481-7.

197. Buffenstein R, Poppitt SD, McDevitt RM, Prentice AM. Food intake and the menstrual cycle: a retrospective analysis, with implications for appetite research. Physiol Behav. 1995;58(6):1067-77.

198. Webb P. 24-hour energy expenditure and the menstrual cycle. Am J Clin Nutr. 1986;44(5):614-9.

199. Lebenstedt M, Platte P, Pirke KM. Reduced resting metabolic rate in athletes with menstrual disorders. Med Sci Sports Exerc. 1999;31(9):1250-6.

200. Wong $\mathrm{CH}$, Siah KW, Lo AW. Estimation of clinical trial success rates and related parameters. Biostatistics. 2019:20(2):273-86.

\section{Publisher's Note}

Springer Nature remains neutral with regard to jurisdictional claims in published maps and institutional affiliations. 